\title{
LEUKOENCEPHALOPATHY WITH BRAINSTEM AND SPINAL CORD INVOLVEMENT AND HIGH BRAIN LACTATE
}

\section{Report of three Brazilian patients}

\author{
Daniel Gurgel Fernandes Távora', Mauro Nakayama', Rômulo Lopes Gama', \\ Thereza Cristina de Lara Alvim', Dalton Portugal'2, Enio Alberto Comerlato ${ }^{3}$
}

\begin{abstract}
A novel leukoencephalopathy was recently identified based on magnetic resonance imaging (MRI) and proton magnetic resonance spectroscopy ('H-MRS) findings. Leukoencephalopathy with brainstem and spinal cord involvement and high lactate (LBSL) is an autosomal recessive disorder characterized by early onset of symptoms and slowly progressive cerebellar, pyramidal and spinal cord dorsal column dysfunction. MRI and ${ }^{1} \mathrm{H}-\mathrm{MRS}$ typically show abnormalities within cerebral and cerebellar white matter, a characteristic involvement of brainstem and spinal cord tracts and elevated lactate in the abnormal white matter. We present three cases with characteristic clinical and neuroimaging findings of this disorder. Some additional unique findings of our patients are discussed, like distal motor neuropathy and elevated creatine kinase in the serum.
\end{abstract}

KEY WORDS: leukoencephalopathy, brainstem, spinal cord, lactate.

\begin{abstract}
Leucoencefalopatia com envolvimento do tronco cerebral e da medula espinal e elevação do lactato cerebral: relato de três casos brasileiros

RESUMO - Uma nova leucoencefalopatia foi recentemente descrita com base em achados característicos de ressonância magnética e espectroscopia de prótons por ressonância magnética. Leucoencefalopatia com envolvimento do tronco cerebral e da medula espinal e elevação do lactato cerebral é uma doença autossômica recessiva de aparecimento precoce e evolução lenta, caracterizada por disfunção cerebelar, piramidal e das colunas dorsais da medula. Ressonância magnética e espectroscopia de prótons tipicamente demonstram anormalidades na substância branca cerebral e cerebelar, com envolvimento característico de tratos no tronco encefálico e na medula espinhal e aumento de lactato na substância branca cerebral anormal. Relatamos três casos com achados clínicos e de neuroimagem característicos. Achados adicionais peculiares aos nossos pacientes são discutidos, como a elevação da creatina-quinase sérica e a presença de neuropatia motora distal.
\end{abstract}

PALAVRAS-CHAVE: leucoencefalopatia, tronco cerebral, medula espinal, lactato.

Approximately half of childhood leukoencephalopathies remain unclassified despite extensive investigation ${ }^{1}$. Recently, some of them have been identified and categorized based on their distinct abnormalities detected on magnetic resonance imaging $(\mathrm{MRI})^{2-6}$. A novel distinct leukoencephalopathy was described in 2003 by Van der Knaap et al. ${ }^{7}$ Symptoms begin during childhood, with slow progression. Distinctive clinical findings include cerebellar, pyrami- dal and dorsal column dysfunction. Laboratory investigation is unrevealing. Typical findings on MRI and proton magnetic resonance spectroscopy ('H-MRS) include abnormal cerebral and cerebellar white matter, brainstem and spinal cord tracts and elevated lactate (Lac) within the abnormal white matter. This recently identified disease has been called leukoencephalopathy with brainstem and spinal cord involvement and high lactate (LBSL).

\footnotetext{
The Sarah Network of Hospitals for Rehabilitation, Fortaleza CE, Brazil: Departments of ${ }^{1}$ Radiology, ${ }^{2}$ Clinical Neurology and ${ }^{3} \mathrm{Clini}-$
} cal Neurophysiology.

Received 22 September 2006, received in final form 15 December 2006. Accepted 7 March 2007.

Dr. Daniel Gurgel Fernandes Távora - Avenida Juscelino Kubitscheck 4500 - 60861-620 Fortaleza CE - Brasil. E-mail: danielgurgel@ sarah.br 
We describe three cases with clinical, neurophysiologic, laboratory, MRI and ${ }^{1} \mathrm{H}-\mathrm{MRS}$ findings suggestive of this new entity.

\section{METHOD}

We have studied three patients from two unrelated families. All patients were born in the same geographic area, in the northeast region of Brazil. Patients 1 and 2 are siblings. A careful interview regarding family history was taken and an experienced neurologist performed a detailed clinical evaluation. Assessment of muscle strength was performed using the Medical Research Council scale.

Laboratory studies included blood cell count, blood gases, glucose, ammonium-ion, uric acid, transaminases, creatine kinase, lactate, thyroid function tests, ceruloplasmin, vitamin E, vitamin B12, folic acid, very long-chain fatty acids, phytanic acid, acanthocytes, plasma amino acids, lysosomal enzymes; Urine: oligosaccharides, sialic acid, amino acids and organic acids; Cerebrospinal fluid (CSF): cell count, protein, lactate, immunoglobulin G index, antibody detection of Herpes simplex virus (HSV), Cytomegalovirus (CMV), Epstein-Barr virus (EBV), toxoplasmosis, schistosomiasis, molecular detection of Mycobacterium tuberculosis and detection of cryptococcal antigen.

Neurophysiologic evaluation was performed according to standard methods ${ }^{8}$. Electroneuromyography (ENMG) and somatosensory-evoked potentials (SEP) were performed in all patients; motor evoked potentials (MEP) and brainstem auditory evoked potentials (BAEP) were performed in patient 1 and visual evoked potentials (VEP) was performed in patients 1 and 3 .

${ }^{1} \mathrm{H}-\mathrm{MRS}$ and MRI of the brain and spinal cord were performed in all patients in the same 1.5T MR unit (Signa Horizon, GE Medical Systems, Milwaukee, WI, USA). Brain MRI protocol included axial and coronal fast spin echo (FSE) T2weighted, axial fluid attenuated inversion recovery (FLAIR), axial and sagittal spin echo (SE) T1-weighted images. Spinal cord MRI included axial and sagittal FSE T1 and T2weighted sequences. T1-weighted sequences were acquired before and after intravenous injection of a paramagnetic contrast agent (gadolinium). Single-voxel point-resolved proton spectroscopy sequences (PRESS) with echo time (TE) of 35 and 144 msec were obtained in the abnormal cerebral white matter. Patient 1 had an additional ${ }^{1} \mathrm{H}-\mathrm{MRS}$ study with voxel located at the abnormal cerebellar white matter. Voxels were $2 \times 2 \times 2 \mathrm{~cm}$ in size. N- acetylaspartate (NAA) was assigned at 2.02 parts per million (ppm), choline (Cho) at $3.2 \mathrm{ppm}$ and creatine $(\mathrm{Cr})$ at $3.03 \mathrm{ppm}$. Metabolite ratios (NAA/Cr and $\mathrm{Cho} / \mathrm{Cr}$ ) were measured. All data processing was performed by software provided by the manufacturer. Patient 3 had a follow-up with MRI and ${ }^{1} \mathrm{H}$-MRS two years apart.

Institutional review board approval was obtained. Verbal consent was obtained from all parents.

\section{RESULTS}

Clinical findings (Table 1) - Patient 1 is a boy, born in 1992. Patients 1 and 2 are siblings. He has two other unaffected siblings. His parents are healthy and nonconsanguineous. He developed a supported walking at 15 months. During subsequent years, he acquired an independent but not mature gait, with frequent falls. At the age of 9, gait pattern began to deteriorate, and nowadays he is not able to walk without support. He has always had learning difficulties. On examination, he has generally depressed deep tendon reflexes, extension plantar response bilaterally, bilateral pes cavus deformity, bilateral lower limb impaired vibration sense, reduced muscle strength for proximal and distal lower limbs and mild to moderate postural/gait ataxia.

Patient 2 is a boy, born in 1987. He acquired normal gait at 12 months. At the age of 6 , he developed progressive walking abnormality, and by the age of 16 years, walking aids were needed for ambulation. On examination, deep tendon reflexes were generally depressed, with extension plantar response bilaterally, bilateral pes cavus deformity, bilateral lower limb impaired vibration sense, decreased tactile and pin sensation in hands and feet, mild to moderate postural/gait ataxia. Muscle strength was reduced for proximal and distal lower limbs.

Patient 3 is a boy, born in 1987 from healthy nonconsanguineous parents. Progressive motor disabilities initiated by the age of 6 years. At 12 years of age he became wheelchair bound. Upper limbs motor deficits were first noted by the age of 14 years. Cognitive impairment was never observed. Examination demonstrated quadriparesis predominant in the distal part of upper and lower limbs, muscular atrophy at thenar and hypothenar regions, generally depressed deep tendon reflexes, mildly impaired vibration and joint-position sense and altered finger-tonose test bilaterally.

Laboratory investigation revealed mildly elevated serum creatine kinase in patient $2(286 \mathrm{UI} / \mathrm{L})$ and in patient 3 (520 UI/L - normal values <190UI/L). The remaining blood, CSF and urine tests were unremarkable.

Neurophysiologic findings are shown in Table 1.

MRI and ${ }^{1} \mathrm{H}$-MRS (Table 2) - MRI revealed high signal intensity in T2-weighted and FLAIR images within the cerebral periventricular and deep white matter sparing U-fibers in all patients. Signal changes were inhomogeneous, confluent, involving all lobes, predominating within frontal and parietal regions in patients 1 and 2 (Figs $1 \mathrm{~A}$ and $2 \mathrm{~A}$ ). In patient 3, signal abnormalities were less prominent, with spotty aspect, affecting exclusively the frontal and parietal 
Table 1. LBSL: Clinical and neurophysiologic features in three patients.

\begin{tabular}{|c|c|c|c|}
\hline & \multicolumn{3}{|c|}{ Patients } \\
\hline & 1 & 2 & 3 \\
\hline Age $(y r) / S e x$ & $13 /$ male & $18 /$ male & $18 /$ male \\
\hline Affected/unaffected siblings & $1 / 2$ & $1 / 2$ & - \\
\hline Age at onset (yr) & 3 & 6 & 6 \\
\hline Initial motor development & $\mathrm{n}$ & $\mathrm{n}$ & $\mathrm{n}$ \\
\hline Initial symptoms & Gait ataxia & Gait ataxia & Gait ataxia \\
\hline Lost unsupported walking (yr) & 12 & 16 & 12 \\
\hline Muscle strength & $\downarrow$ & $\downarrow$ & $\downarrow$ \\
\hline Sensory function & Distal $\downarrow$ & Distal $\downarrow$ & Distal $\downarrow$ \\
\hline Deep tendon reflexes & $\downarrow$ & $\downarrow$ & $\downarrow$ \\
\hline Babinski sign & Bilateral + & Bilateral + & Bilateral + \\
\hline Cognitive function & Learning problems & Learning problems & $\mathrm{n}$ \\
\hline SNAP & $\mathrm{n}$ & $\mathrm{n}$ & $\mathrm{n}$ \\
\hline NCV & $\mathrm{n}$ & $\mathrm{n}$ & Motor $\downarrow$ \\
\hline ENMG & $\begin{array}{l}\text { Chronic denervation } \\
\text { in distal muscles }\end{array}$ & $\begin{array}{l}\text { Chronic denervation } \\
\text { in distal muscles }\end{array}$ & $\begin{array}{l}\text { Chronic denervation in } \\
\text { proximal and distal muscles }\end{array}$ \\
\hline SEP & Delayed & Delayed & - \\
\hline MEP & Prolonged & Prolonged & Prolonged \\
\hline VEP & $\mathrm{n}$ & - & $\mathrm{n}$ \\
\hline BAEP & $\mathrm{n}$ & - & - \\
\hline
\end{tabular}

n, normal; yr, year; $\downarrow$, decreased; +, present; -, not done; SNAP, sensory nerve action potential; NCV, nerve conduction velocity; ENMG, electroneuromyography; SEP, somatosensory-evoked potentials; MEP, motor evoked potentials; VEP, visual evoked potentials; BAEP, brainstem auditory evoked potentials.
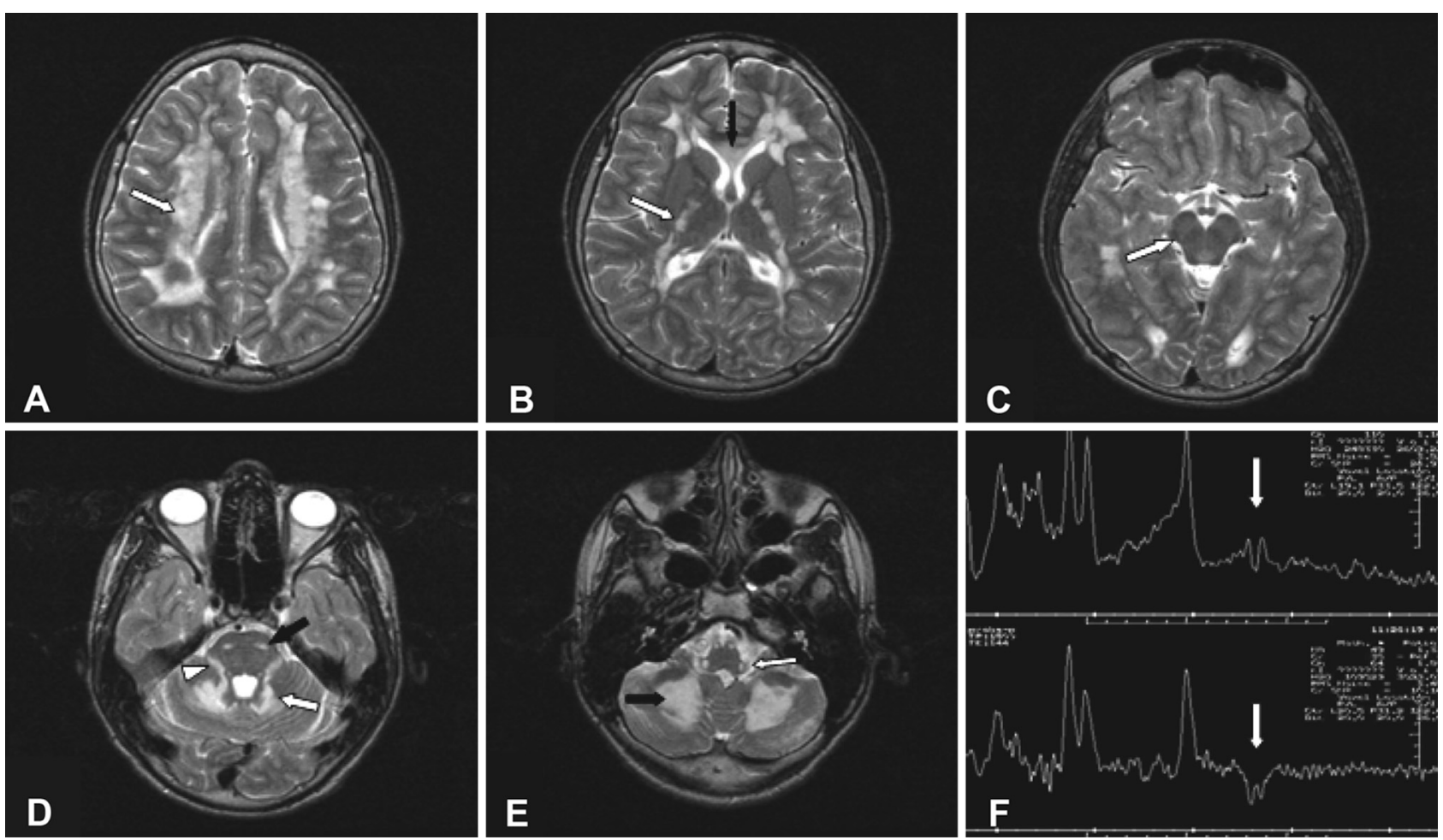

Fig 1. Axial T2-weighted images of the brain (A-E) and ${ }^{1} H-M R S$ spectra (F) in patient 1. The hemispheric white matter shows confluent signal abnormalities (A). There is involvement of the anterior part of the corpus callosum (black arrow in B), posterior limb of internal capsule (white arrow in B), intraparenchymal trajectory of trigeminal nerves (arrowhead in D) superior cerebellar peduncles (white arrow in D), pyramidal tract (black arrow in D), inferior cerebellar peduncles (white arrow in E) and cerebellar white matter (black arrow in E). Within the midbrain there is no signal alteration (C). ${ }^{1} \mathrm{H}-\mathrm{MRS}$ spectra at TE=35ms (upper spectrum) and 144 ms show abnormal doublet indicating elevated Lac (arrows in F). 
Table 2. LBSL: MRI findings in three patients.

\begin{tabular}{|c|c|c|c|}
\hline & \multicolumn{3}{|c|}{ Patients } \\
\hline & 1 & 2 & 3 \\
\hline Cerebral white matter & +/extensive, diffuse & +/extensive, diffuse & + / spotty \\
\hline \multicolumn{4}{|l|}{ Corpus callosum } \\
\hline Atrophy & + & + & - \\
\hline High signal & genu / splenium & splenium & splenium \\
\hline Posterior limb of internal capsule & + & + & - \\
\hline \multicolumn{4}{|l|}{ Cerebellar white matter } \\
\hline Subcortical & + & - & + \\
\hline Deep & + & + & - \\
\hline Midbrain & - & - & - \\
\hline \multicolumn{4}{|l|}{ Pons } \\
\hline Transverse pontine fibers & - & - & - \\
\hline Pyramidal tracts & + & + & + \\
\hline Medial lemniscus & - & - & - \\
\hline Superior cerebellar peduncles & + & + & + \\
\hline Mesencephalic trigeminal tracts & + & + & + \\
\hline Intrapyramidal trigeminal nerve & + & + & + \\
\hline \multicolumn{4}{|l|}{ Medulla } \\
\hline Pyramids & + & + & + \\
\hline Medial lemniscus & + & + & - \\
\hline Inferior cerebellar peduncles & + & + & + \\
\hline Anterior spinocerebellar tracts & + & - & - \\
\hline \multicolumn{4}{|l|}{${ }^{1} \mathrm{H}-\mathrm{MRS}$} \\
\hline Elevated lactate & + & - & + \\
\hline Elevated Cho/Cr & + & - & - \\
\hline \multicolumn{4}{|l|}{ Spinal cord } \\
\hline Posterior columns & + & + & + \\
\hline Lateral corticospinal tracts & + & + & + \\
\hline
\end{tabular}

+, affected ; -, unaffected; Cho, Choline; Cr, Creatine.

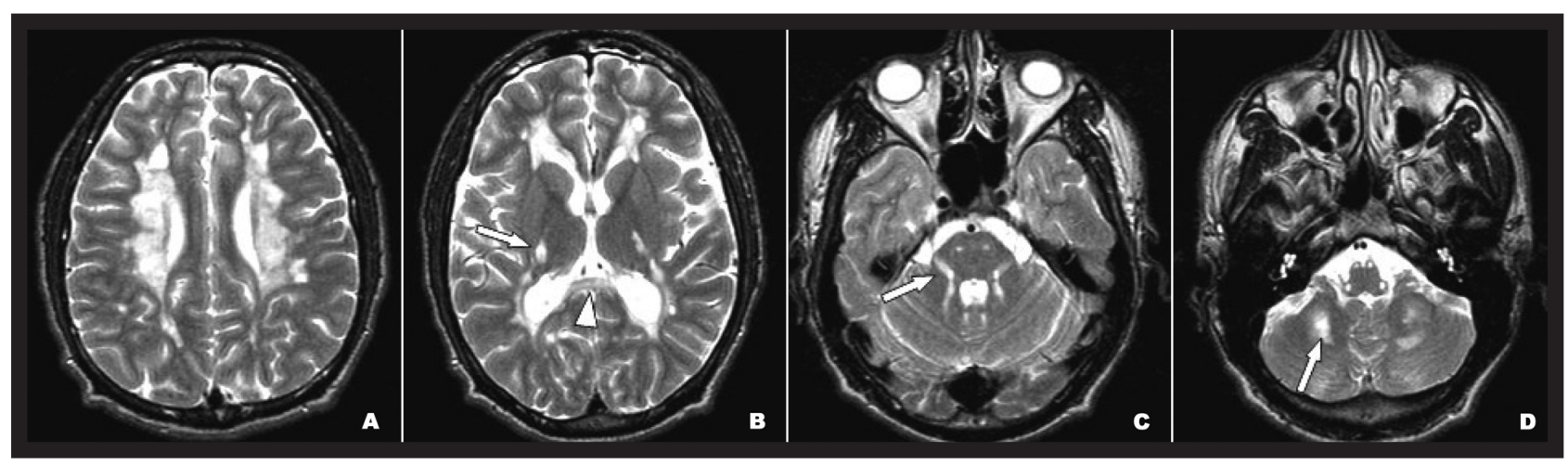

Fig 2. Axial T2-weighted images of the brain in patient 2 shows diffuse abnormalities in the cerebral white matter (A), altered signal of the posterior limb of internal capsule (white arrow in B), splenium of the corpus callosum (arrowhead in B), intraparenchymal trajectory o trigeminal nerves (white arrow in C) and deep cerebellar white matter (arrow in D).

lobes. Corpus callosum was thin in patients 1 and 2, with diffuse signal abnormality in patient 1 . Patients 2 and 3 had signal changes restricted to the splenium (Fig 2B). Posterior limb of internal capsules were altered in patients 1 and 2 (Figs $1 \mathrm{~B}$ and $2 \mathrm{~B}$ ), and normal in patient 3.
There were no abnormalities within the midbrain and transverse pontine fibers.

The following structures were affected in all patients: pyramidal tracts at the level of the pons and medulla, pyramids, intraparenchymal trajectory of trigeminal nerves, mesencephalic trigeminal tracts, 
inferior and superior cerebellar peduncles (Figs 1D$\mathrm{E}$ and $2 \mathrm{C}$ ).

Anterior spinocerebellar tracts were mildly involved in patient 1 . Medial lemniscus was affected at the level of the medulla in patients 1 and 2 .

Cerebellum was also affected with diffuse white matter involvement in patient 1 , deep white matter involvement in patient 2 (Figs $1 \mathrm{E}$ and $2 \mathrm{D}$ ), and mild subcortical alterations in patient 3.

${ }^{1} \mathrm{H}$-MRS showed a doublet at $1.3 \mathrm{ppm}$, compatible with elevated Lac, and higher $\mathrm{Cho} / \mathrm{Cr}$ within abnormal cerebellar white matter in patient 1 (Figure 1F) and within frontoparietal white matter in patient 3.

Spinal MRI revealed abnormal signal in the dorsal columns and lateral corticospinal tracts in all patients (Fig 3).

No contrast enhancement was observed in the post-gadolinium T1-weighted images.

Patient 3 had a follow-up brain and spinal MRI two years apart. There was a mild increase in subcortical cerebellar white matter abnormalities as the only change noticed.

\section{DISCUSSION}

A novel leukoencephalopathy was described in children by Van der Knaap et al. based on clinical and MRI features ${ }^{7}$. To our knowledge, only ten additional cases with similar clinical and MRI findings have been demonstrated ${ }^{9,10}$. Neurological symptoms frequently start in childhood and progress slowly. Initial complaints refer to gait instability and tremor. Muscle weakness, cerebellar ataxia and distal spasticity, most prominent in lower limbs, become more pronounced during disease progression. Cognitive impairment is observed in some patients. Patients typically develop decreased distal position and vibration sense. Clinical features of the present patients were similar to the formerly described cases (Table 1). Laboratory investigation revealed elevated creatine kinase in patients 2 (286 UI/L) and 3 (520 UI/L). To our knowledge this finding has not been previously described and we attributed it to motor axonal neuropathy.

Neurophysiologic findings were indicative of involvement of the posterior columns, cortico-spinal tracts, and lower motor neurons (LMN). In two patients ENMG revealed chronic partial denevertionreinervation in upper and lower limbs, with distal muscles affected more severely than proximal muscles, suggesting distal motor neuropathy ${ }^{9}$. One patient had diffuse anterior cell dysfunction, probably due to advanced disease stage. These alterations have not been described in LBSL patients. ${ }^{7,9}$ Border-

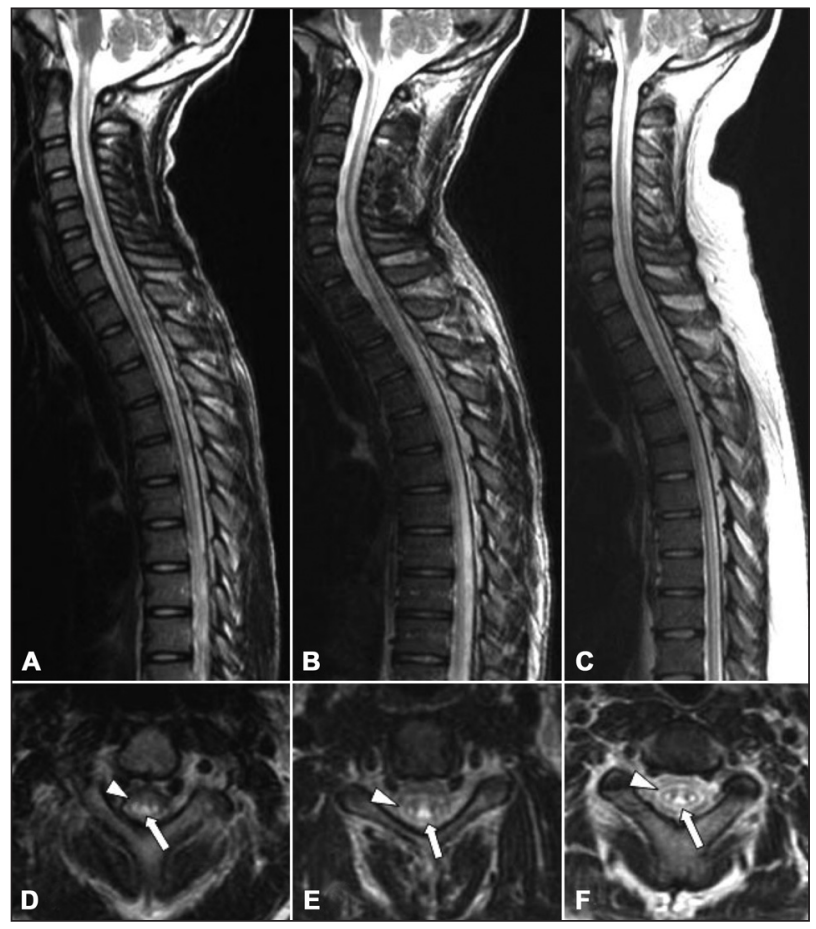

Fig 3. Sagittal T2-weighted images of the spine of patients 1 (A), 2 (B) and $3(C)$, indicating longitudinal involvement. Axial T2-weighted images of patients $1(D), 2(E)$ and $3(F)$, demonstrating abnormal signal in the dorsal columns (arrows) and lateral corticospinal tracts (arrowheads).

line reduction of nerve conduction velocities has already been reported ${ }^{7,9}$. Peripheral sensory system, visual and brainstem auditory pathways were spared in these three patients.

MRI and ${ }^{1} \mathrm{H}-\mathrm{MRS}$ findings were unique and correlated to previous reports (Table 2). Cerebral white matter was involved to a variable extent, with inhomogeneous, confluent, extensive signal abnormality in patients 1 and 2, and a spotty abnormal signal in patient 3. Correlation of clinical severity and MRI findings have already been verified ${ }^{7,9}$. One of our patients (patient 3) had minor cerebral white matter involvement and was the only one with preserved cognitive function. Subcortical U-fibers were spared in all patients.

Posterior corpus callosum had altered signal intensity in all cases. Abnormal signal at the genu was detected only in patient one. Diffuse atrophy of the corpus callosum was present in patients 1 and 2 .

Patient 3 had no abnormality in the posterior limbs of the internal capsules. This finding is in contrast with previous reports ${ }^{7,9-10}$, which homogeneously detected involvement of this anatomical structure. Cerebellar white matter was involved diffusely in pa- 
tient 1 and subcortical signal change was found in patient 3. On the other hand, patient 2 showed mild abnormality affecting merely deep cerebellar white matter, a finding not described on previous series.

Midbrain had no signal intensity abnormality and this is an atypical finding in our patients. Nevertheless, Serkov et al. ${ }^{10}$ described normal medial lemniscus and pyramidal tracts within the midbrain in two out of five patients described.

Within the pons, neither medial lemniscus nor the transverse pontine fibers were affected. Transverse pontine fibers are not invariably involved in previously reported cases. Altered signal usually becomes apparent in late stages ${ }^{2}$. Medial lemniscus signal abnormality at this level is a common finding, but not always present ${ }^{7}$. Anatomical_structures consistently affected in our cases within the pons included the pyramidal tracts, superior cerebellar peduncles, mesencephalic trigeminal tracts, and intrapyramidal trigeminal nerve.

Anterior spinocerebellar tract involvement is a usual finding ${ }^{7}$, but not invariably present ${ }^{9}$. The pyramids and inferior cerebellar peduncles were always abnormal within the medulla. Medial lemniscus was abnormal in two patients and anterior spinocerebellar tract in only one.

Previous reports have emphasized the involvement of the sensory and pyramidal tracts over their entire length ${ }^{9,10,12}$. Conversely, in our cases we have not detected MRI abnormalities within the midbrain and have not found involvement of the medial lemniscus at the level of the pons. Actually, one of the previous reports have also found normal signal intensity in the pyramidal tracts and medial lemniscus in some cases at the level of the pons and midbrain ${ }^{10}$.

Spinal cord MRI revealed altered signal in posterior columns and lateral corticospinal tracts over the entire length in all cases. These abnormalities are in absolute agreement with earlier reports.

${ }^{1} \mathrm{H}-\mathrm{MRS}$ revealed increased Lac in two out of three cases. Elevated Lac is considered a criterion for the definition of this entity, but is not absolutely present in all cases reported earlier ${ }^{8,12}$. Elevated Cho has variably been found in previous reported series ${ }^{7,9}$ and was detected only in patient 1 . It is possibly due to mildly enhanced membrane turnover and myelin loss. ${ }^{13}$

The involvement of two siblings in the present cases reinforces the likelihood of an autosomal recessive mode of inheritance. Consistent data on the pathogenetic mechanisms of this disease are still lacking on current literature. The genetic defect is unknown and no pathology information is available ${ }^{13}$.

In conclusion, we have described three Brazilian patients with overall clinical and imaging features compatible with LBSL. Some features observed by us have not been previously reported, like elevated creatine kinase in the serum and neurophysiologic evidence of distal motor neuropathy. Moreover, we would like to call attention to the discontinuous aspect of the MRI signal abnormalities in the sensory and pyramidal tracts in our patients.

\section{REFERENCES}

1. Van der Knaap MS, Breiter SN, Naidu S, Hart AAM, Valk J. Defining and categorizing leukoencephalopathies of unknown origin: MR imaging approach. Radiology 1999;213:121-133.

2. Van der Knaap MS, Barth PG, Stroink H, et al. Leukoencephalopathy with swelling and a discrepantly mild clinical course in eight children. Ann Neurol 1995;37:324-334.

3. Hanefeld F, Holzbach U, Kruse B, Willichowski E, Christen H-J, Frahm J. Diffuse white matter disease in three children: an encephalopathy with unique features on magnetic resonance and proton magnetic resonance spectroscopy. Neuropediatrics 1993;24:244-248.

4. Van der Knaap MS, Barth PG, Gabreëls FJM, et al. A new leukoencephalopathy with vanishing white matter. Neurology 1997;48:845-855.

5. Cavalcanti CE, Nogueira A. Síndrome de Van der Knaap - megalencefalia com leucodistrofia: a respeito de dois casos na mesma família. Arq NeuroPsiquiatr 2000;58:157-161.

6. Oliveira HA, Machado ML, Jesus ACF, et al. Leucoencefalopatia megalencefálica com substância branca evanescente e cistos subcorticais. Arq Neuropsiquiatr 2004;62:1058-1062.

7. Van der Knaap MS, Van der Voorn P, Barkhof F, et al. A new leukoencephalopathy with brainstem and spinal cord involvement and high lactate. Ann Neurol 2003;53:252-258.

8. Recommendations for the practice of clinical neurophysiology: guidelines of the International Federation of Clinical Neuroohysiology. Electroencephalogr Clin Neurophysiol 1999;52(Suppl):S1-S304.

9. Linnankivi T, Lundbom N, Autti T, et al. Five new cases of a recently described leukoencephalopathy with high brain lactate. Neurology 2004;63:688-692

10. Serkov SV, Pronin IN, Bykova OV, et al. Five patients with a recently described novel leukoencephalopathy with brainstem and spinal cord involvement and elevated lactate. Neuropediatrics 2004;35:1-5.

11. De Jonghe P, Auer-Grumbach J, Irobi K, et al. Autosomal dominant juvenile amyotrophic lateral sclerosis and distal hereditary motor neuronopathy with pyramidal tract sings: synonyms for the same disorder? Brain 2002;125:1320-1325.

12. Chiffmann R, Van der Knaap MS. The latest on leukodystrophies. Curr Opin Neurol 2004; 17:187-192.

13. Marjo S. van der Knaap, Jaap Valk. Magnetic resonance of myelination and myelin disorders. 3.Ed. New York: Springer, 2005:510-517. 